\title{
A CARTOGRAFIA ANALÓGICA E DIGITAL NO ENSINO DE GEOGRAFIA: MAPEAMENTO DO USO E OCUPAÇÃO DO SOLO COM ALUNOS DO ENSINO FUNDAMENTAL
}

\author{
Maurício Rizzatti ${ }^{(a)}$ Natália Lampert Batista ${ }^{(b)}$ Roberto Cassol ${ }^{(c)}$ Iago Turba Costa ${ }^{(d)}$ \\ (a) Mestrando em Geografia, Universidade Federal de Santa Maria, E-mail: geo.mauricio.rizzatti@gmail.com \\ (b) Doutoranda em Geografia, Universidade Federal de Santa Maria, E-mail: natilbaista3 @ gmail.com \\ (c) Prof. Dr. do Departamento de Geociências, Universidade Federal de Santa Maria, E-mail: rtocassol@gmail.com \\ (d) Acadêmico do Curso de Geografia, Universidade Federal de Santa Maria, E-mail: iagoturba@ hotmail.com
}

EIXO: GEOGRAFIA FÍSICA: CURRÍCULO, FORMAÇÃO E PRÁTICAS DE ENSINO

\begin{abstract}
Resumo
A Cartografia é de fundamental relevância pois permite aos estudantes a interpretação de mapas como linguagem de comunicação, podendo ser usado no cotidiano. Assim, esse trabalho tem como objetivo avaliar a eficiência do uso de geotecnologias, ligadas ao Sensoriamento Remoto, como recurso didático no ensino fundamental. Realizou-se a sequência didática na E.M.E.F. J/AO CAIC "Luizinho de Grandi" com o sexto ano verde, em 2016. Primeiramente, aplicou-se um questionário para verificar a compreensão prévia por parte dos alunos. Após, teve uma exposição teórica sobre conceitos cartográficos a fim de ampliar o conhecimento dos estudantes. Posteriormente, ocorreu a elaboração dos mapas de uso e ocupação do solo (manual/digital) e, novamente a aplicação de um questionário para verificar o entendimento das temáticas desenvolvidas. Conclui-se que a sequência didática realizada serviu para os discentes entenderem como ocorre o processo de mapeamento, além da interpretação da legenda, obtendo assim, leituras de síntese do espaço em que residem.
\end{abstract}

Palavras chave: Mapemamento, QGIS, , Cartografia Escolar, Sensoriamenro Remoto

\section{Introdução}

$\mathrm{O}$ mundo, especialmente após a segunda metade do século XX, permitiu um enorme avanço das novas tecnologias de informação e comunicação. Dentre elas, destacam-se as imagens orbitais (ou imagens de satélites artificiais) e também o Sistema de Posicionamento Global. Partindo desse princípio, várias empresas elaboraram programas que utilizavam essas imagens para demostrar o espaço geográfico, como é o caso da Google, com o Google Earth e a Agência Espacial Norte-Americana (NASA) com o Virtual Earth.

A partir do fim da Guerra Fria, a linguagem dos mapas fica associada à era da informação. A tecnologia tornou o mapa um sistema de informações geográficas. A coleta, o armazenamento, a recuperação, o processamento, a análise e a síntese dos dados, permite uma representação capaz de revelar informações sobre lugares ao longo do tempo (MARTINELLI, 2009). 


\section{OS DESAFIOS DA GEOGRAFIA FÍSICA NA FRONTEIRA DO CONHECIMENTO \\ Instituto de Geociências - Unicamp \\ Campinas - SP \\ 28 de Junho à 02 de Julho de 2017}

Neste contexto, surge o sensoriamento remoto, que fornecem dados sobre alvos na superfície sem que haja um contato direto entre eles. Todas as imagens de satélite são produtos do sensoriamento remoto. É uma importante ferramenta para identificação, monitoramento e analise dos problemas ambientais. Sendo assim, considera-se muito relevante o uso desta tecnologia na educação básica (SAUSEN et al., 1997). Os Parâmetros Curriculares Nacionais reforçam o uso de tecnologias voltadas à educação, como a do sensoriamento remoto, que faz parte do universo das geotecnologias.

Essas tecnologias formam uma ferramenta para o processo de ensino-aprendizagem, que vem cooperar para uma melhor compreensão do espaço geográfico. Estão próximas ao cotidiano das pessoas, em especial de jovens e de crianças, na qual estão inseridas no mundo tecnológico.

Para não distanciar do dia a dia dos alunos, a escola precisa rever suas práticas metodológicas para que possa acompanhar o desenvolvimento acelerado das tecnologias, colocando-as no processo de ensinoaprendizagem. Na educação, as transformações não ocorrem de maneira tão rápida como na tecnologia, gerando um distanciamento a ser superado (BRASIL, 2001). Segundo Martins (2011, p.65) “é necessário construir habilidades e competências para atuar num mundo recheado de tecnologias, privilegiando práticas transformadoras".

Isso também é visto nos temas transversais dos Parâmetros Curriculares Nacionais, que evidenciam o uso o aprendizado pelas novas tecnologias e que conviver com produtos científicos e tecnológicos é algo universal hoje. A falta da informação cientifica-tecnológica pode comprometer a própria cidadania, pois tecnologia e ciência são heranças culturais. (BRASIL, 1998a).

A contribuição das geotecnologias no ensino é observada no trabalho de Santos (2002). Para a autora:

No ensino de Geografia, a utilização de imagens de satélite, por exemplo, permite identificar e relacionar elementos naturais e socioeconômicos presentes na paisagem, tais como serra, planícies rios, bacias hidrográficas, matas, áreas agriculturáveis, indústrias, cidades, bem como acompanhar resultados a dinâmica de seu uso, servindo, portanto, como um importante subsídio à compreensão das relações sociais e de suas consequências no uso e ocupação dos espaços (SANTOS, 2002, p.57).

Nesse contexto das geotecnologias, o Sistema de Informação Geográfica (SIG), permite a utilização de imagens geradas através do sensoriamento remoto, onde é possível identificar elementos naturais e socioeconômicos da paisagem. Conforme Florenzano (2002), em que a partir da análise e interpretação das imagens de sensores remotos podem ser articulados os conceitos geográficos de lugar, localização, além de interação homem/meio.

Oliveira (2006) menciona que os recursos computacionais permitem uma maior capacidade de geração de modelos e uma maior velocidade de execução de estudos visuais possibilitando a representação do tempo 
e do espaço nas composições gráficas e permitindo uma nova forma de pensar e de entender a realidade e ao interagir com ele, o aluno se sente motivado em relação ao seu espaço de análise. Nesse sentido, conforme Batista (2015)

Para a realização da leitura crítica de um mapa é preciso que o educando compreenda que essa representação possui um vínculo direto com a representação do espaço, vivido ou ausente. Além disso, é preciso explorar os diversos elementos que compõe a representação cartográfica. Os símbolos, as cores e as relações que existem com o mundo. As representações cartográficas ultrapassam a mera descrição do espaço. São subsídios indispensáveis à tomada de decisão e a espacialização dos elementos que o compõem (BATISTA, 2015, p. 89).

A utilização de mapas nas aulas de Geografia é bastante notório, embora, grande parte das vezes, o professor disponibilize apenas "mapas prontos" "aos estudantes, fato que não colabora para desenvolver um aluno mapeador. Isso ocorre porque os discentes não possuem um conhecimento sobre a sua construção e também sobre os signos presentes no mesmo (RIZZATTI, 2016). Assim, o professor necessita vincular as aulas tradicionais às aulas inovadoras que despertem a imaginação dos alunos, passando a utilizar recursos didáticos como: trabalhos práticos com mapas virtuais, fotografias aéreas, imagens de satélite entre outros recursos para obter maior eficácia no processo de ensino-aprendizagem e despertar a criatividade dos educandos. (BRASIL, 1998b).

Segundo os Parâmetros Curriculares Nacionais (1998c)

Desde as primeiras etapas da escolaridade, o ensino da Geografia pode e deve ter como objetivo mostrar ao aluno que cidadania é também o sentimento de pertencer a uma realidade em que as relações entre a sociedade e a natureza formam um todo integrado (constantemente em transformação) do qual ele faz parte e que, portanto, precisa conhecer e do qual se pinta membro participante, afetivamente ligado, responsável e comprometido historicamente. (BRASIL, 1998c, p.29)

Nesse sentido, nota-se a importância do educando entender como é a realidade onde vive, e que ele faz parte dela, para posteriormente fazer comparações com outros lugares. Baseado nisso, as geotecnologias, dentre as quais o sensoriamento remoto e o SIG são um recurso tecnológico que pode despertar a curiosidade no aluno e ajudar na compreensão do espaço geográfico, podendo fazer comparações com outros lugares.

Com base nisso, o presente artigo tem como objetivo geral avaliar a eficiência do uso de geotecnologias, ligadas ao Sensoriamento Remoto, como recurso didático no ensino fundamental. Para aprofundar e detalhar o objetivo apresentado tem-se os específicos: compreender o que é o alfabeto cartográfico e qual a sua aplicação; verificar a compreensão dos alunos ao identificar os elementos naturais e artificiais

\footnotetext{
${ }^{1}$ Referem-se às representações cartográficas presentes em livros didáticos ou atlas, que já estão finalizados, isto é, com a presença de meridianos e paralelos, cores, legenda, escala e orientação, cabendo ao aluno somente a sua interpretação.
} 

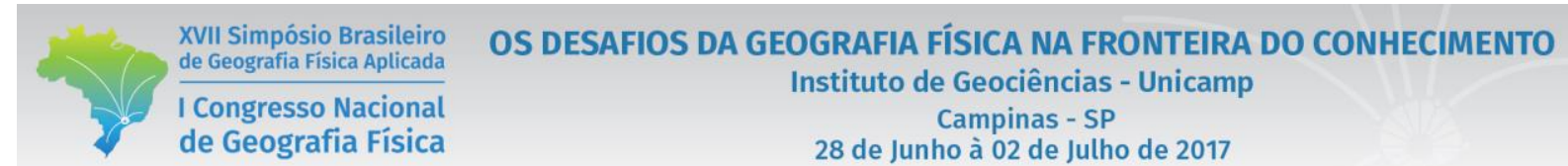

presentes na paisagem; identificar a motivação dos alunos ao trabalhar com recursos geotecnológicos e analógicos, e despertar a curiosidade pelo uso de recursos tecnológicos para fins de aprendizagem.

\section{Metodologia}

Para a concretização dos objetivos elencados, primeiramente foi realizado um levantamento bibliográfico sobre Sistema de Informação Geográfica (SIG) e sensoriamento remoto aplicado ao ensino. Posteriormente, teve o início a aplicação da sequência didática na E.M.E.F. J/AO CAIC "Luizinho de Grandi”, localizada no bairro Lorenzi, no município de Santa Maria, RS, conforme exposto na figura 1. Nesse momento, os alunos do $6^{\circ}$ ano verde ${ }^{2}$ responderam um questionário para verificar a compreensão (prévia) sobre a temática.

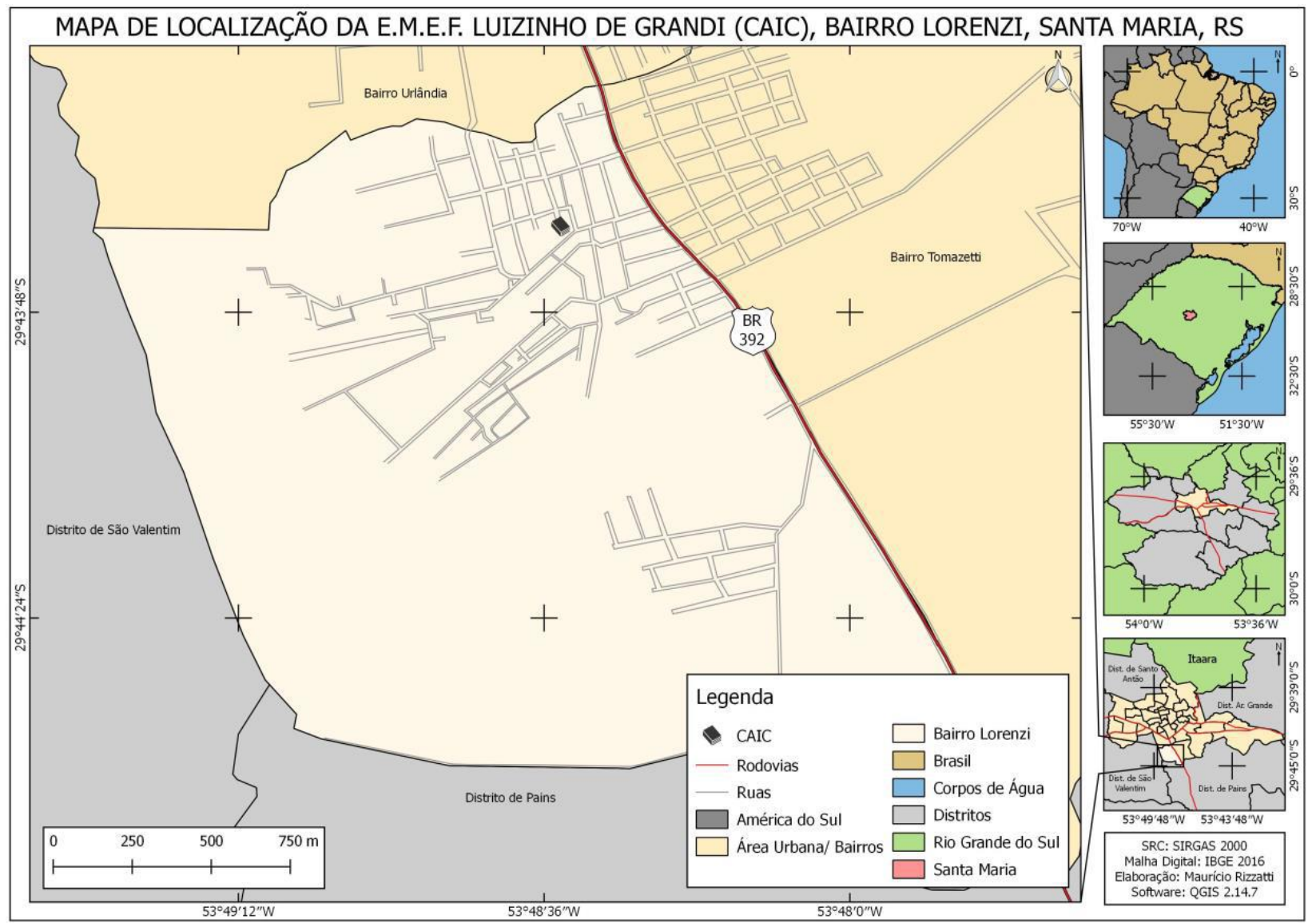

Figura 1 - Mapa de Localização da E.M.E.F. Luizinho de Grandi (CAIC), Santa Maria, RS.

Fonte: Rizzatti, 2016.

${ }^{2}$ A instituição de ensino na qual a sequência didática foi desenvolvida atribuí cores para identificar as turmas. 


\section{OS DESAFIOS DA GEOGRAFIA FÍSICA NA FRONTEIRA DO CONHECIMENTO \\ Instituto de Geociências - Unicamp \\ Campinas - SP \\ 28 de Junho à 02 de Julho de 2017}

No próximo encontro, realizou-se a exposição teórica utilizando recursos tecnológicos para ampliar o conhecimento dos alunos sobre sensoriamento remoto, conceitos cartográficos (em especial o alfabeto cartográfico), técnicas para identificar feições naturais e culturais, bem como noções básicas sobre SIG.

Após a exposição dos conceitos, os alunos receberam uma imagem do Google Earth dos bairros: Lorenzi (bairro da escola), Dom Antônio Reis, Urlândia e Tomazetti, que são bairros vizinhos ao local onde foi aplicada a atividade, onde residem grande parte dos alunos, e um papel vegetal, na qual delimitaram as feições presentes nos bairros, por exemplo: área urbanizada, campos, mata ciliar e lavouras. Após, é disponibilizada a mesma imagem (dos bairros mencionados) em formato digital para que sejam identificadas as mesmas feições no SIG, gerando assim, mapas de uso e ocupação da terra de modo analógico e digital.

Para finalizar a atividade, novamente foi aplicado um questionário para avaliar os conhecimentos desenvolvidos para verificar se os alunos ampliaram seu entendimento sobre sensoriamento remoto, bem como verificar a motivação dos alunos com a atividade proposta, e a curiosidade proporcionada pelas geotecnologias para o desenvolvimento do trabalho e para fins de estudo.

\section{Resultados e discussões}

O $6^{\circ}$ ano verde possui 21 alunos, dos quais 14 deles são do gênero feminino e os outros 7 estudantes são do gênero masculino. De toda a turma, $90 \%$ residem no bairro Lorenzi e o restante (10\%) moram no bairro Tomazetti. Por esse motivo, as áreas mapeadas são do bairro Lorenzi e os (bairros) vizinhos, produzidos de modo analógico e digital, conforme ilustrado na figura 2. Na figura 3 e 4, têm-se exemplos dos mapas produzidos pelos estudantes. 


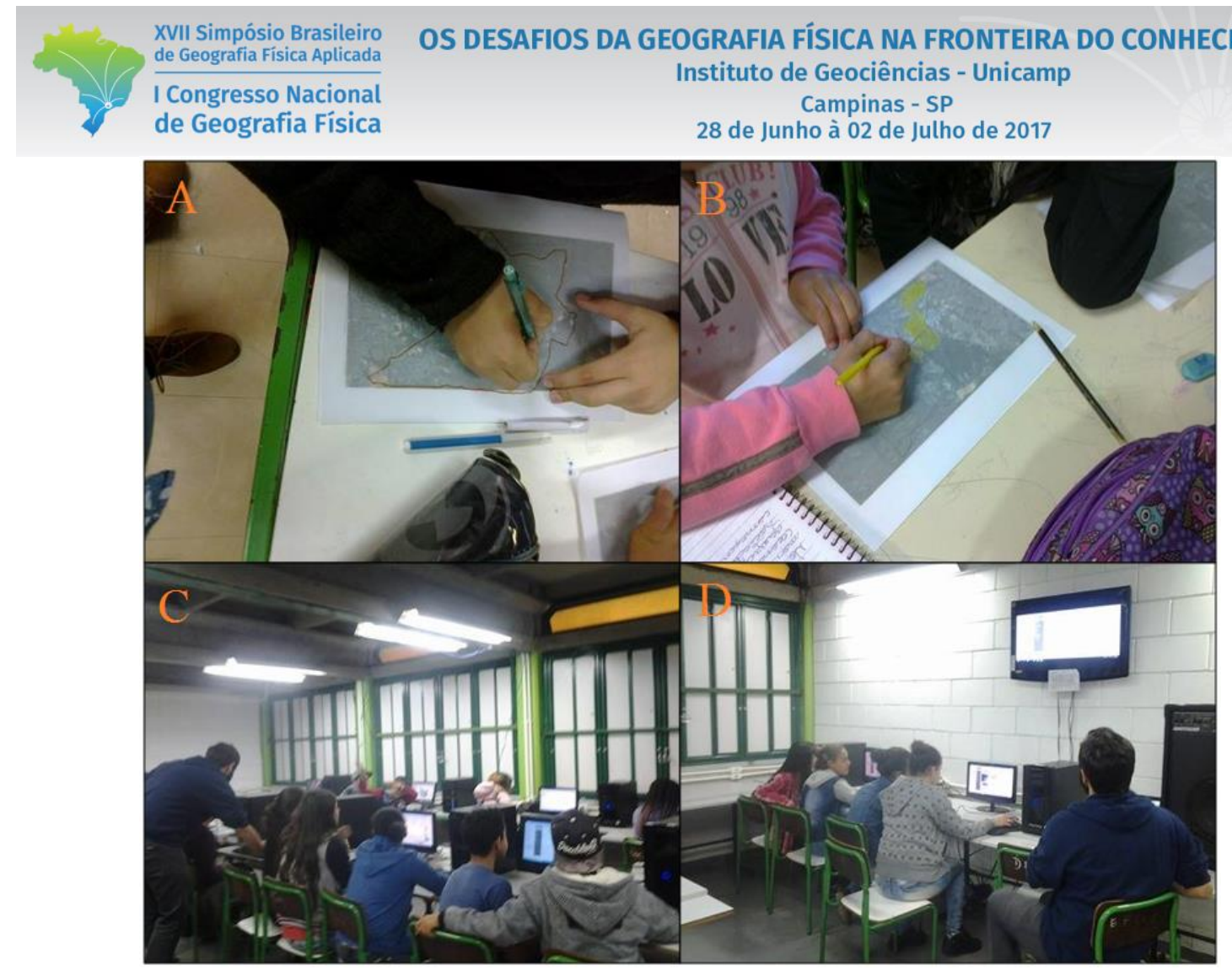

Figura 2 - Confecção dos mapas de uso e ocupação do solo: analógico (A e B) e digital (C e D)

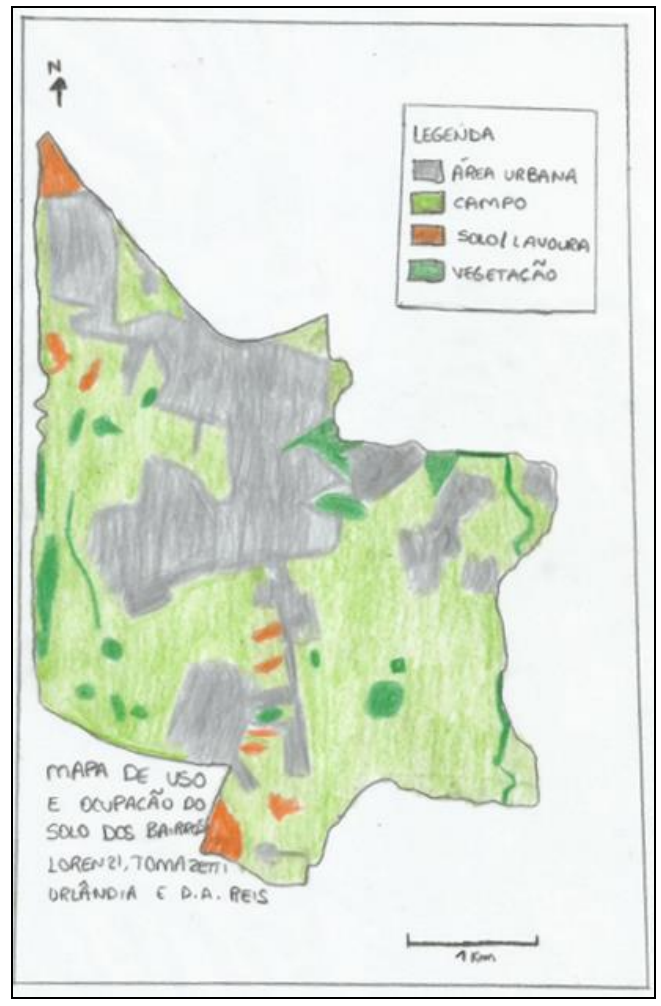

Figura 3 - Mapa de uso e ocupação do solo (manual) dos bairros Lorenzi, Tomazetti, Urlândia e Dom Antônio Reis 


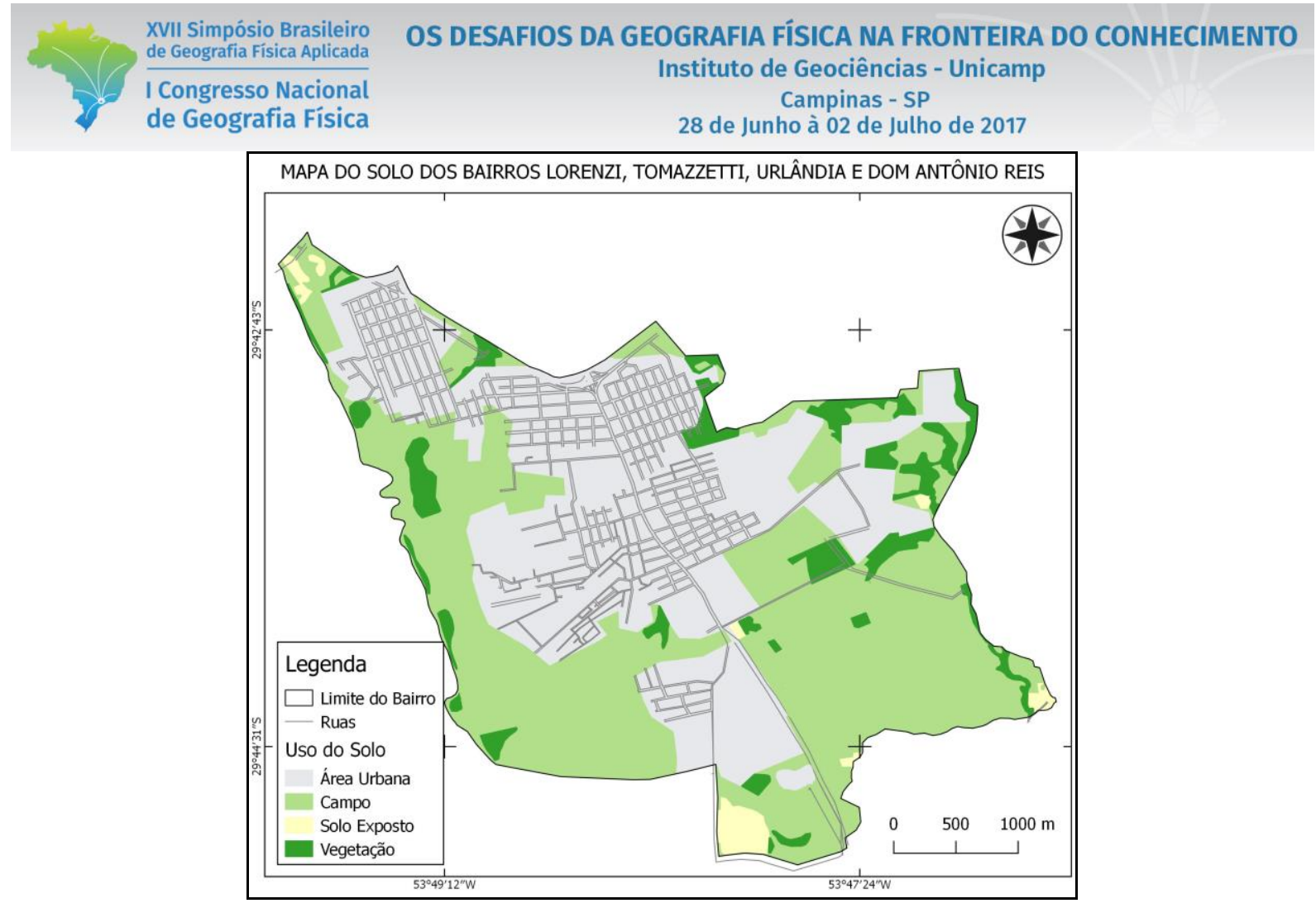

Figura 4 - Mapa de uso e ocupação do solo (digital) dos bairros Lorenzi, Tomazetti, Urlândia e Dom Antônio Reis

Tratando-se da motivação dos estudantes sobre o uso de geotecnologias no ambiente escolar, no primeiro questionário, 95\% dos alunos acham interessante o uso de geotecnologias nas aulas de Geografia, enquanto $5 \%$, não responderam. Já no segundo questionário, todos os alunos aprovaram a utilização de imagens aéreas e SIG na escola, conforme a aluna A. S. D. "Achei interessante porque mostra que a internet não foi feita apenas para a rede sociais, mas também nos ajudar no estudo. Porque é mais eficiente para nós procurar coisas que necessitamos nos estudos". A ilustração das respostas pode ser visualizada na figura 5 .

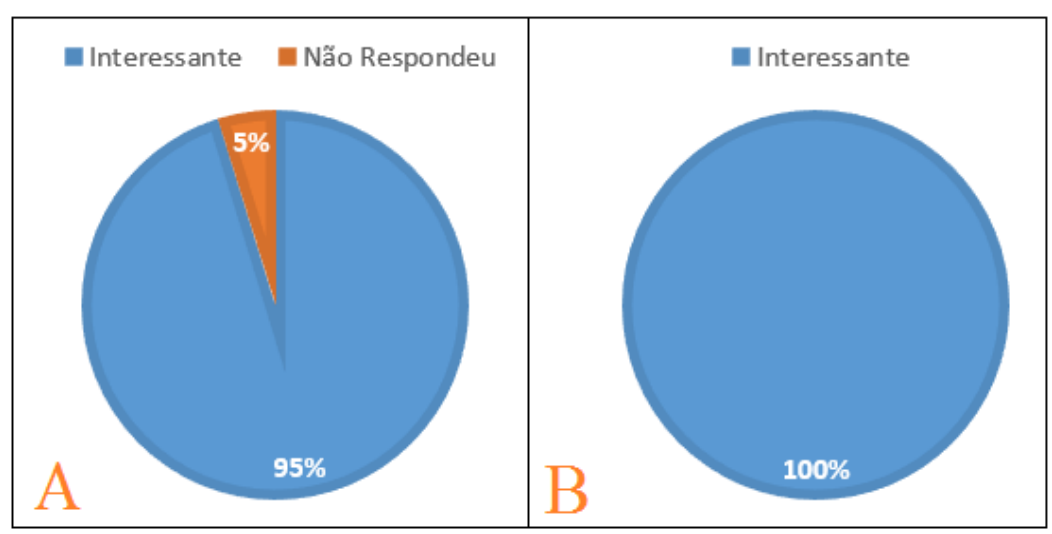

Figura 5 - Respostas dos estudantes sobre o uso de geotecnologias no questionário prévio (A) e posterior (B) a atividade desenvolvida 


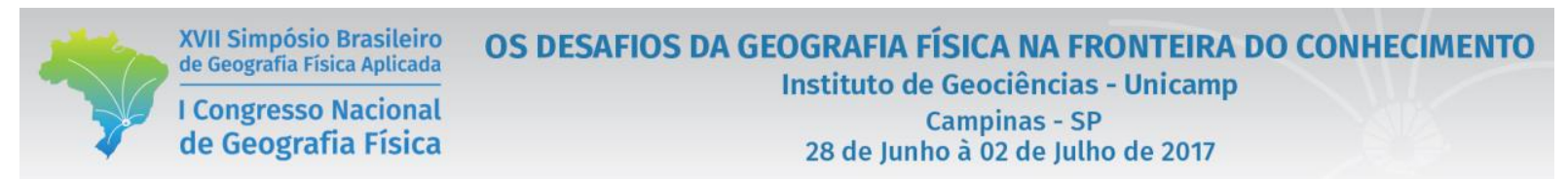

A segunda interrogativa do questionário aplicado previamente à atividade dizia respeito como as imagens aéreas (ou satélite) são produzidas. Dos 21 discentes da referida turma, $76 \%$ afirmaram não saber como se dá a confecção das imagens; $19 \%$ responderam ser por um satélite e 5\% disseram ser por meio de um avião que tira foto do planeta. Já na avaliação após a realização da atividade, $48 \%$ dos alunos apresentaram uma assimilação do conceito, visto que responderam é através do satélite que capta a energia refletida pelo planeta Terra. Já $24 \%$ dos discentes aferiram não saber a resposta, enquanto $19 \%$ apresentaram o conceito em partes e outros 9\% ressaltaram a importância (e uso) das imagens de satélite, conforme exposto na figura 6 .

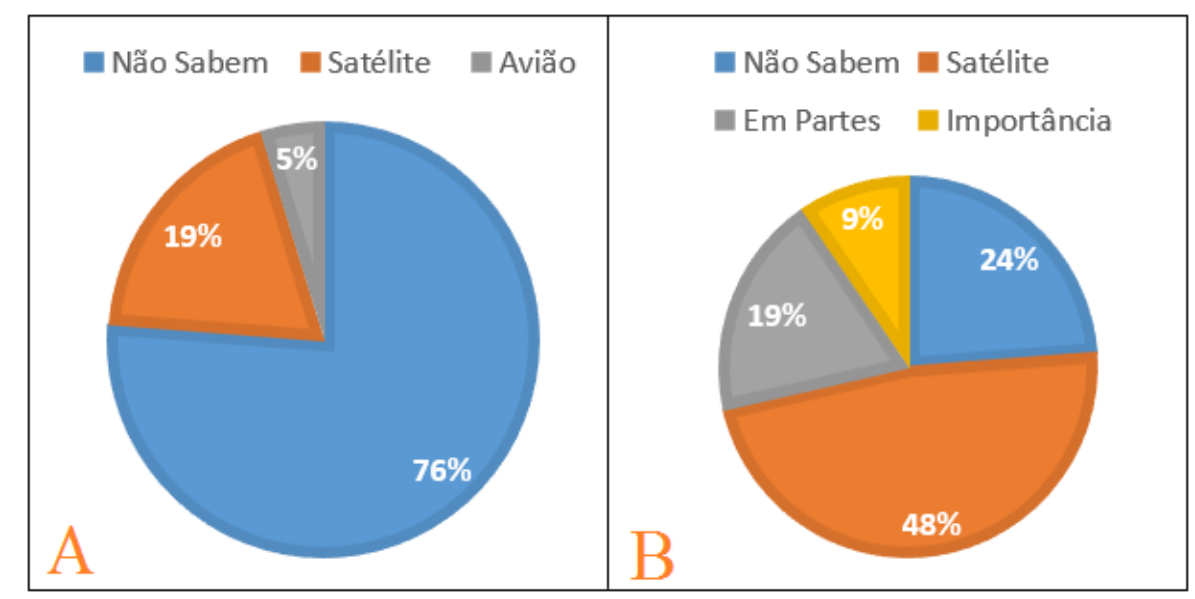

Figura 6 - Respostas das estudantes sobre a confecção de imagens de satélite (ou aéreas) no questionário prévio (A) e posterior (B) a atividade desenvolvida

A próxima questão referia-se se os alunos sabiam elaborar um mapa e se aprenderam a confeccionar. No questionário aplicado anteriormente a atividade, 95\% dos alunos afirmaram não saber e teriam interesse em aprender a produzir um mapa, enquanto $5 \%$ dos alunos respondeu que não gostaria de aprender. $\mathrm{Na}$ avaliação, após a aplicação da atividade, questionaram-se os procedimentos necessários para a produção de um mapa de uso de solo. Do total de 21 alunos da turma, 71\% apresentaram os passos corretamente, demonstrando compreender como ocorre tal tarefa (produção do mapa), 19\% não entenderam e outros $10 \%$ entenderam parcialmente, pois não mencionaram um ou dois procedimentos. As respostas encontram-se ilustradas na figura 7. 


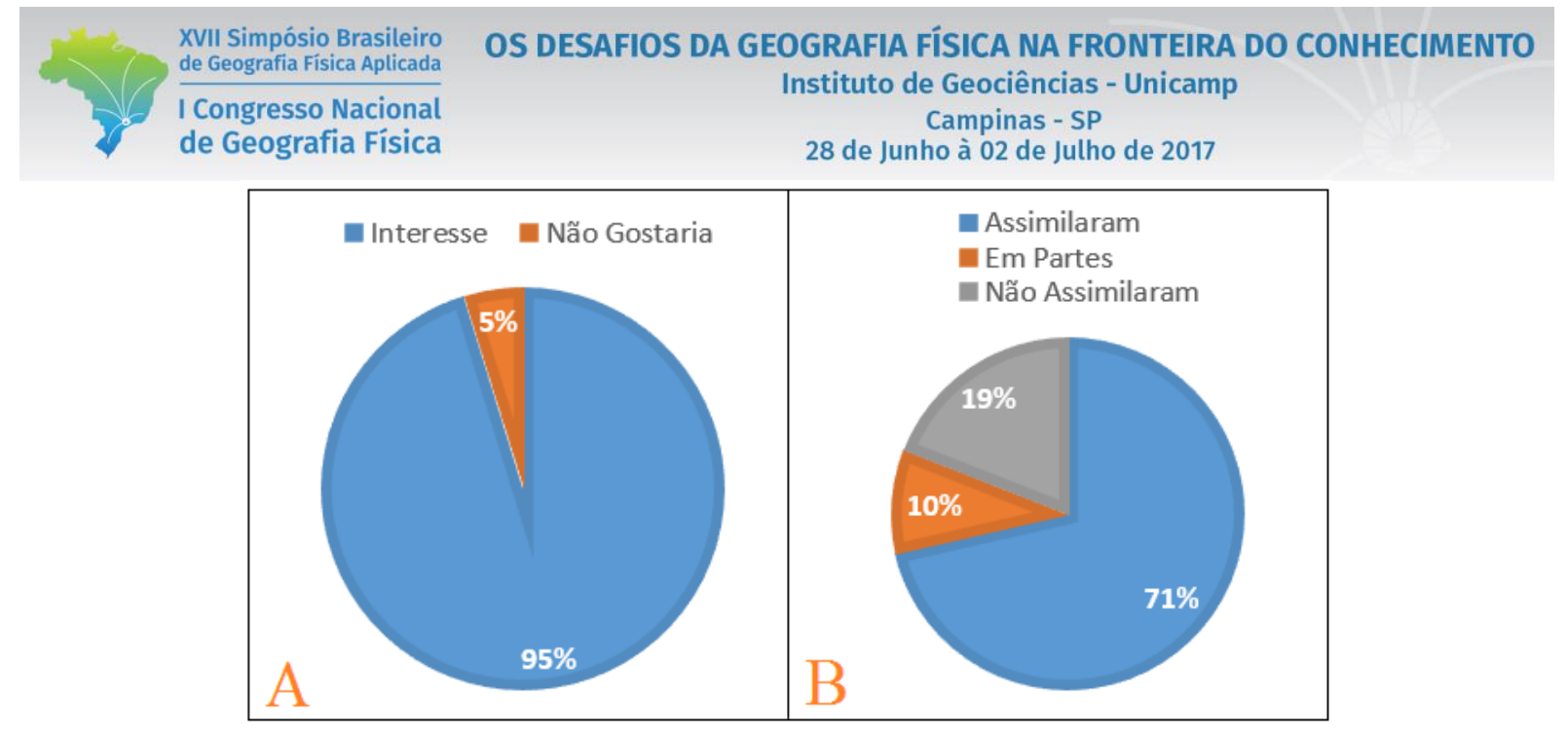

Figura 7 - Opinião dos estudantes a respeito se gostariam de elaborar um mapa (A) e se compreenderam os procedimentos de confecção (B).

A quarta questão tratava-se de como os elementos (ruas/rodovias e área urbana) são representados nos mapas, que, para isso, fora disponibilizado no questionário um mapa de Santa Maria. Sobre a representação das rodovias no mapa, 57\% dos alunos afirmaram não saber a resposta; $33 \%$ responderam que é por meio de uma linha, demonstrando uma compreensão previa sobre a temática; $5 \%$ disseram que é através dos emblemas (código das rodovias) e outros 5\% não responderam. Na avaliação posterior, $81 \%$ dos estudantes afirmaram ser pela linha, $14 \%$ com a utilização de um traço e 5\% não responderam, conforme exposto na figura 8 .

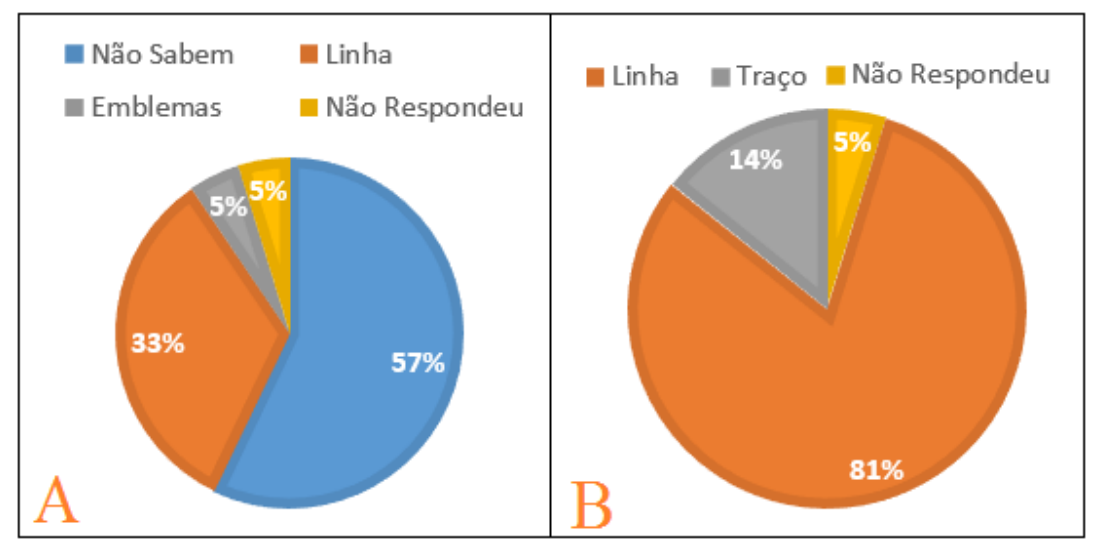

Figura 8 - Resposta dos estudantes para a representação das rodovias nos mapas no questionário prévio (A) e posterior a atividade realizada (B).

Organização: Os autores

Sobre a área urbana, 62\% dos discentes afirmaram não saber como é a representação da mesma; $33 \%$ dos alunos não responderam e 5\% disseram ser por de um quadrado. Na avaliação posterior a realização do projeto, $62 \%$ dos estudantes aferiram que a representação da área urbana se dá na forma de polígono, 24\% 


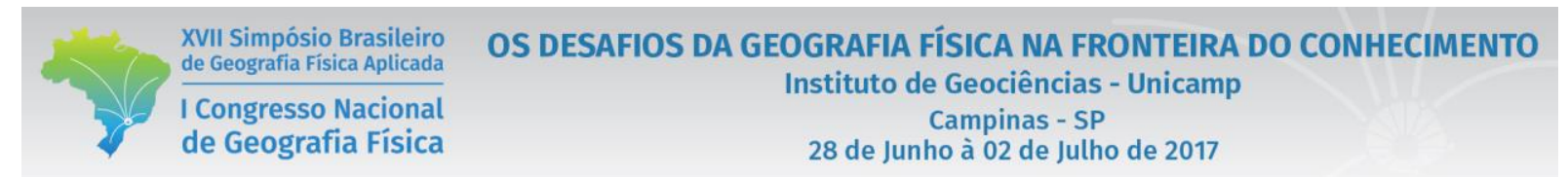

dos educandos responderam pela cor cinza; $9 \%$ afirmou ser através de um quadrado e outro aluno (5\%) não responderam à interrogativa, conforme a figura 9.

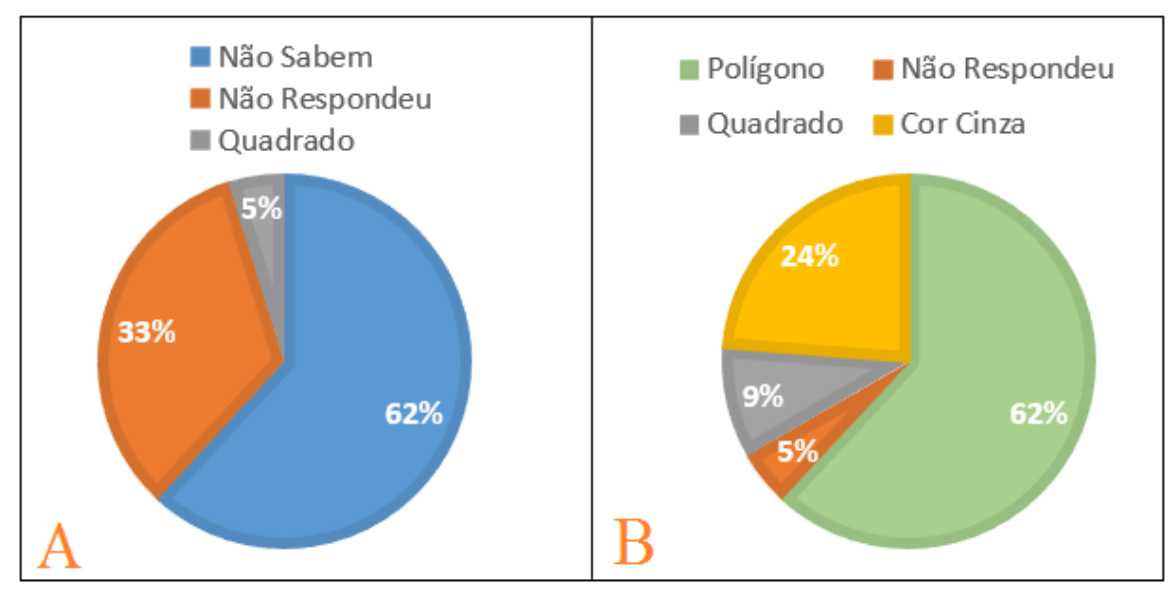

Figura 9 - Resposta dos estudantes para a representação da área urbana nos mapas no questionário prévio (A) e posterior a atividade realizada $(\mathrm{B})$.

Organização: Os autores

O último questionamento refere-se à identificação de elementos naturais e artificiais em documentos cartográficos. No primeiro questionário, os estudantes deveriam identificar os elementos presentes em uma imagem do Google Earth do bairro Lorenzi. Dos 21 alunos da turma, 33\% deles conceituaram e localizaram os elementos, demonstrando um conhecimento sobre interpretação de uma imagem aérea; $57 \%$ dos estudantes aferiram não saber interpretar o documento e $10 \%$ não responderam. No segundo questionário, deveriam identificar esses elementos por meio do mapa de uso e ocupação de solo, elaborado pelos próprios discentes (figura 4). Nesse sentido, 86\% dos alunos apresentaram o conceito assimilado, localizando e classificando os diferentes usos de solo em paisagens naturais e artificiais; 9\% dos estudantes não responderam e um (5\%) apresentou uma assimilação em partes, visto que, classificou campo como paisagem artificial, mas o restante (área urbana e vegetação) teve uma compreensão do que se estava perguntando. As respostas dos estudantes estão ilustradas na figura 10. 


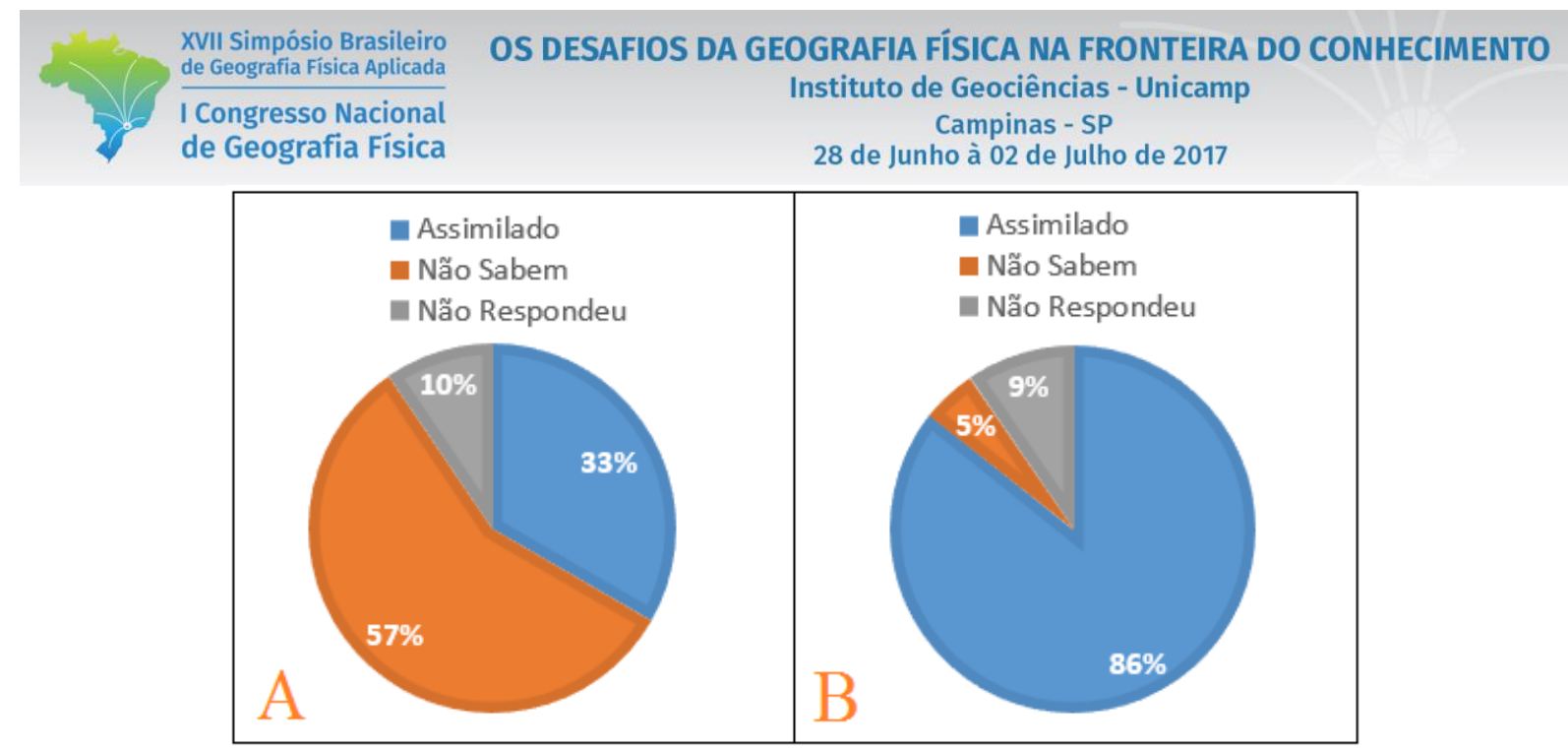

Figura 10 - Resposta dos estudantes para de paisagens naturais e artificiais em documentos cartográficos no questionário prévio (A) e posterior a atividade realizada (B).

Organização: Os autores

\section{Considerações finais}

Através do exposto, foi possível visualizar que os alunos estavam bastante curiosos para a realização da atividade, desde primeiro contato com a turma, visto que se encontravam instigados a respeito da produção dos mapas do espaço que residem. Na atividade pedagógica, os alunos contribuíram dando sua opinião a respeito do bairro Lorenzi, demonstrando percepção do espaço vivido.

Os discentes tiveram uma ampliação do conhecimento se comparado o primeiro questionário com o segundo, no que diz respeito à confecção das imagens de satélites (ou aéreas), a grande maioria dos alunos da turma forneceram respostas convincentes quando questionados se aprenderam a elaborar os mapas de uso e ocupação do solo. Nesse sentido, destaca-se a importância de o aluno participar ativamente do processo de mapeamento, para possuir noção da metodologia de confecção do mapa, além disso, também é necessário fornecer atividades que auxiliam na leitura e compreensão de documentos cartográficos.

Conclui-se que os educandos compreenderam o que é o alfabeto cartográfico e seu uso, visto que responderam os questionamentos, bem como fizeram uso do mesmo para a produção dos mapas (analógico e digital). Além disso, demonstraram uma excelente leitura da legenda para a compreensão e identificação das diferentes paisagens que estavam representadas nos mapas. Também, ressalta-se a importância de softwares de mapeamentos livres, como no caso do QGIS, já que a linguagem tecnológica é fundamental no ambiente escolar, já que os mesmos têm contato com a mesma cotidianamente e a escola não pode se distanciar dessa realidade. 


\section{REFERÊNCIAS}

BATISTA, N. L. A Cartografia Escolar no processo de ensino-aprendizagem: o Hipermapa e sua utilização na Educação Ambiental, em Quevedos/RS. (Dissertação de Mestrado). Programa de Pós-Graduação em Geografia. Santa Maria: Universidade Federal de Santa Maria, 2015.

BRASIL. Ministério da Educação e do Desporto. Parâmetros Curriculares Nacionais. Brasília: MEC/SEF, 1998b.

BRASIL. Ministério da Educação. Secretária da Educação Média e Tecnológica. Parâmetros Curriculares Nacionais: Ensino Médio. Brasília, São José dos Campos: MEC/Univap. 2001.

BRASIL. Secretaria de Educação Fundamental. Parâmetros curriculares nacionais: Ciências Naturais /Secretaria de Educação Fundamental. Brasília: MEC /SEF, 1998a.

BRASIL. Secretaria de Educação Fundamental. Parâmetros curriculares nacionais: Geografia / Secretaria de Educação Fundamental. Brasília: MEC/ SEF, 1998c.

FLOREZANO, T. G. Imagens de Satélite para Estudos Ambientais. São Paulo: Oficina de Textos, 2002.

MARTINELLI, M. Mapas, gráficos e redes. São Paulo: Oficina de Textos, 2009.

MARTINS, R. E. M. A trajetória da geografia e o seu ensino no século XXI. In: TONINI, I. M. et al (Org.). O ensino de geografia e suas composições curriculares. Porto Alegre: UFRGS, 2011. p. 61-75.

OLIVEIRA, K. A. S. Do ponto ao pixel: novas mídias, novas linguagens. (Dissertação de Mestrado). Mestrado Área de Concentração: Design e Arquitetura. São Paulo: FAUUS, 2006.

RIZZATTI, M. Cartografia Escolar, geotecnologias e a Teoria das Inteligências Múltiplas: a construção de conhecimentos geográficos no ensino fundamental (Trabalho de Graduação). Universidade Federal de Santa Maria, Centro de Ciências Naturais e Exatas, Departamento de Geociências, Curso de Geografia - Licenciatura Plena, RS, 2016.

SANTOS, V. M. N. dos. Escola, cidadania e novas tecnologias: o sensoriamento remoto no ensino. São Paulo: Paulinas, 2002.

SAUSEN, T. M.; CARVALHO, V. C.; SERAFINI, M. C.; FACCIO, J. M. H.; PIRES, I. O.; COSTA, S. M. F. Documento de Camboriú. In: I Jornada de educação em sensoriamento remoto no âmbito do Mercosul. Camboriú, SC, 20-23 de maio de 1997. 